\title{
Global variation in the cost of increasing ecosystem carbon
}

\author{
Larjavaara, Markku
}

2018-01

Larjavaara , M , Kanninen , M , Ruesta , H G , Koskinen , J , Kukkonen , M , Käyhkö , N , Larson, A M \& Wunder , S 2018 , ' Global variation in the cost of increasing ecosystem carbon ' , Nature Climate Change , vol. 8 , no. 1 , pp. 38-42 . https://doi.org/10.1038/s41558-017-0015-7

http://hdl.handle.net/10138/321587

https://doi.org/10.1038/s41558-017-0015-7

unspecified

acceptedVersion

Downloaded from Helda, University of Helsinki institutional repository.

This is an electronic reprint of the original article.

This reprint may differ from the original in pagination and typographic detail.

Please cite the original version. 


\section{Global variation in the cost of increasing ecosystem carbon}

Markku Larjavaara $^{1 *}$, Markku Kanninen ${ }^{1,2}$, Harold Gordillo Ruesta ${ }^{3}$, Joni Koskinen ${ }^{4}$, Markus Kukkonen $^{4,5}$, Niina Käyhkö ${ }^{4}$, Anne M. Larson ${ }^{6}$ \& Sven Wunder ${ }^{6}$

${ }^{1}$ Viikki Tropical Resources Institute (VITRI), Department of Forest Sciences, PO Box 27, 00014 University of Helsinki, Helsinki, Finland. ${ }^{2}$ Center for International Forestry Research (CIFOR), Bogor, Indonesia. ${ }^{3}$ Niras. Ratatie 11, 01300 Vantaa, Finland. ${ }^{4}$ Department of Geosciences and Geography, University of Helsinki, 00014 Helsinki, Finland. ${ }^{5}$ Department of Geography and Geology, University of Turku, 20014 Turku. ${ }^{6}$ Center for International Forestry Research (CIFOR), Lima, Peru.

\section{Main text}

Slowing the reduction, or increasing the accumulation, of organic carbon stored in biomass and soils has been suggested as a potentially rapid and cost-effective method to reduce the rate of atmospheric carbon increase ${ }^{1}$. The costs of mitigating climate change by increasing ecosystem carbon relative to the baseline or business-as-usual scenario has been quantified in numerous studies, but results have been contradictory, with both methodological issues and substance differences causing variability ${ }^{2}$. Here we show, based on 77 standardised face-to-face interviews of local experts with best possible knowledge on local land-use economics and socio-political context in ten landscapes around the globe, that the estimated cost of increasing ecosystem carbon varied vastly and was perceived to be 16-27 times cheaper in two Indonesian landscapes compared to the average of the eight other landscapes. Hence, if REDD+ and other land-use mitigation efforts were to be distributed evenly across forested countries, e.g. for the sake of international equity, their overall effectiveness would be dramatically lower than for a cost-minimising distribution.

Changes in agriculture, forestry and other land uses are considered central in the mitigation pathways envisioned by the IPCC ${ }^{6}$. Because deforestation 'business as usual' tends to benefit forestland holders and often even forested countries ${ }^{3}$, a system of compensated deforestation reduction between poor forested and rich countries has been developed ${ }^{4}$. Hundreds of projects aimed at reducing emissions from deforestation and forest degradation (REDD+) and other forest carbon initiatives with similar objectives have been launched ${ }^{5}$. Their combined impact on the global carbon cycle has so far remained modest ${ }^{6}$, but this may change thanks to the signing of the Paris Agreement in early $2016^{(7)}$.

Information on the costs of mitigating climate change is valuable to avoid spending in landscapes with high cost-effectiveness ratios. Forest-based mitigation cost curves have been estimated, from the local to global scale, using household-level field surveys ${ }^{8}$, contracts allocated by inversed auctions ${ }^{9}$, census-based municipal-level data ${ }^{10}$ and global simulation models based on national census data ${ }^{11}$. For example a recent pantropical household survey across 17 different sites finds the time-discounted value of costs per Mg of carbon to vary by more than two orders of magnitude 
from US\$7 to US\$944 ${ }^{(12)}$. Local-level data are generally methodologically complicated to upscale, while census-based approaches often overestimate mitigation costs because agricultural productivity in remote deforestation frontiers often falls markedly short of census-based averages focusing more on modern production systems. Likewise significant risks of poor governance in environmentally fragile frontier regions remain widely unaccounted.

Hence the economic literature gives clues, but certainly no consensus on mitigation costs. Even when only comparing large-scale top-down models, a one-time payment of US\$50 for a reduction of $\mathrm{Mg}$ of atmospheric $\mathrm{CO}_{2}$ directed toward land use (comparable to US $\$ 183.33$ for a sequestered $\mathrm{Mg}$ of carbon) is estimated to trigger an annual global atmospheric carbon reduction from as little as $0.14 \mathrm{Pg}$ to as much as $1.39 \mathrm{Pg}$ or equivalent climate impact by $2030^{(13)}$. Still more uncertainty is unavoidable when comparing local ${ }^{14}$ to global studies ${ }^{15}$. Therefore the IPCC report lists the cost of land use-based mitigation as a knowledge gap ${ }^{13}$.

A well-selected group of local experts may add new knowledge concerning local land-use economics, by being able to combine biogeochemical with socio-political information, such as an understanding of institutional opportunities and barriers or resistance due to perceptions of inequity, in ways that would be very challenging for non-local scholars. Interviewing local experts from around the world, using comparative methods, enables acquiring bottom-up mitigation cost estimates that are open to all mitigation efforts, while accounting for uncertainty caused by variation in expert opinions and carbon data. Below we thus explore this promising pathway for narrowing an important knowledge gap.

Our objective was to interview the best available land-use experts of ten landscapes (Supplementary Data) in five countries and continents (Fig. 1) to elicit their opinions on the cost of increasing ecosystem carbon locally. We conducted eight interviews in each landscape (but only seven in MexicoEast and only six in MexicoWest). We followed a rigid interview structure, beginning with a discussion of the assumptions. We then inquired how land use might change if an annual payment of US\$1 were made for every extra Mg of carbon stocked in the landscape. Finally, we asked the same question with a hypothetical payment of US\$10. In both cases we asked interviewees to assume current conditions except good governance, ensuring efficient local distribution of carbon funding. We coded the interview responses on land-use changes relative to the baseline scenario using a new tool called CarboScen ${ }^{16}$. We made the carbon implications available during the interviews so that the interviewees could modify their responses based on the graphic outputs of the tool.

The ten landscapes had widely differing carbon densities in 2015 (Table 1 and Fig. 2). These ranged from $63 \mathrm{Mg} \mathrm{ha}^{-1}$ in TanzaniaWest, with large areas of grassland, to $4608 \mathrm{Mg} \mathrm{ha}^{-1}$ in IndonesiaEast. The two Indonesian landscapes are mainly peat soils. These were included in the analyses because peat layers are vulnerable to human-caused oxidation, unlike organic carbon at similar depths in mineral soils. Initial carbon density varied modestly in the other eight landscapes, depending mainly on the quality and quantity of remaining forest. We developed baseline scenarios based on plausible land-use changes from 2015 to 2045 and assuming no payments for additional carbon. Of the eight landscapes, only FinlandNorth showed substantial increase in carbon density in thirty years, from 
$130 \mathrm{Mg} \mathrm{ha}^{-1}$ to $139 \mathrm{Mg} \mathrm{ha}^{-1}$. In contrast, the carbon densities in the two Indonesian landscapes were assumed to collapse under the baseline scenario from $4608 \mathrm{Mg} \mathrm{ha}^{-1}$ to $4133 \mathrm{Mg} \mathrm{ha}^{-1}$ and from 1934 $\mathrm{Mg} \mathrm{ha}^{-1}$ to $1546 \mathrm{Mg} \mathrm{ha}^{-1}$, while changes in the baseline scenarios of the other seven landscapes were modest, as shown in Fig. 2.

Carbon additions from our hypothetical performance-based payments varied significantly relative to the reference scenario, even when comparing the means of all interviewed experts for a given landscape. For comparison, instead of equally weighting carbon additions for a fixed period of time and not taking carbon implications thereafter into account, we used the mean carbon density addition discounted by $3 \%$, so that the near future was weighted more than the distant. Based on a hypothetical payment of US\$1, this mean varied 578 -fold, ranging from $0.2 \mathrm{Mg} \mathrm{ha}^{-1}$ in MexicoWest, where all but one of the interviewees did not believe any change would occur, to 105.6 $\mathrm{Mg} \mathrm{ha}^{-1}$ in IndonesiaEast (Table 1). With a payment of US\$10 the range narrowed to 56-fold (Table 1 and Fig. 3). According to the experts, a payment of US\$10 led only to a 1.4-3.6 -fold carbon increase compared to a US\$1 payment, except in MexicoWest where this increase was 14.8fold (Fig. 3). The less than 10-fold carbon change with a 10-fold payment suggests marginally declining returns, so that a cost-effective programme would be based on small payments but over large areas. However, a larger area is likely to increase the monitoring cost per added unit of carbon, thus partially evening out the difference. The differences between landscapes diminish when potential additions are compared to initial carbon densities (Fig. 2) or the nominal potential, i.e. technical maximum (rightmost column in Table 1).

We computed the net carbon changes only, and did not attempt to quantitatively separate changes strengthening positive action, such as reforestation, and weakening negative action, such as deforestation, because their definitions are dependent on spatial and temporal scales. Instead, we qualitatively describe here the envisioned changes. In both Finnish landscapes, the interviewed experts anticipated that most of the carbon increase would result from increasing carbon density on forestry land, with a small amount from afforestation and increasing carbon density on cropland. In the Indonesian landscapes, most actions triggered by hypothetical carbon payments occurred on peatlands. Afforestation and rising water table levels resulted in anticipated changes that conserved some of the peat from oxidisation due to aerobic decomposition ${ }^{17}$ or from fire ${ }^{18}$. Expert responses in MexicoEast were similar to those in Finland, i.e. with increasing carbon density in already forested areas and a small amount of afforestation. In MexicoWest, the experts envisioned, in addition to increasing carbon density of forested areas, a significant afforestation of the area classified as 'Pasture and savannah'. In PeruNorth, the assumed payments triggered carbon increase through 'Coffee' conversion to 'Eco-coffee', i.e. coffee production under shade trees ${ }^{19}$. Experts in PeruSouth anticipated a significant increase in the carbon density of forested land, but, additionally, noteworthy afforestation was predicted on agricultural land. In TanzaniaEast, the experts were unusually unanimous in believing that a modest increase in ecosystem carbon could result from forest tree plantations replacing coral rag scrub. In TanzaniaWest, the potential carbon increase was assumed to result from coniferous tree plantations on various open lands.

The scatter of the lines in Figure 3 reveals the variability in the expert views. Variation was smallest in Finland, likely due to clear land ownership and the common objective of profiting from wood 
production, in addition to the relative ease of envisioning how carbon funding is channelled to forest owners. In contrast, experts in the other landscapes showed large variation in their views, most of which we are unable to explain with the basic information that we report in Supplementary Table 2 or other knowledge that we learned while interviewing. The only exceptions were the two experts (IndonesiaEastD and MexicoEastG) who did not perceive any influence of the finance assumed coming from a global fund. Their views appeared to originate from thinking that their countries and their peasants should remain independent from funds coming from high-income countries.

The local experts are well placed to combine information on local social and political conditions with land-use economics, and it is very likely that they could realistically envision the changes triggered by the hypothetical payments. We avoided similar backgrounds and selected a group that was probably more diverse than if chosen randomly from local experts. Therefore the variation in their responses (Table 1 and Fig. 3) is likely to overestimate uncertainty relative to a random selection. However, the means derived from their responses could still be biased if several of the experts were influenced by the same biased information. For example, we did not ask the interviewees to think out loud, but most of them justified their responses in detail, and it appears that most did not sufficiently consider the potential price increases of agricultural products caused by carbon payments, therefore underestimating the cost of increasing carbon. Nevertheless, we believe that such potential biases are similar in all the landscapes, and, therefore, even if the magnitude is off and comparison to other mitigation options could be biased, comparisons among the landscapes should not be drastically influenced. Hence, our data set offers an unprecedented opportunity to shed new light on the global variation in the cost of increasing ecosystem carbon, and could be compared with studies using completely different methods.

Comparisons to previously published costs of mitigating climate change with land-use change are complicated by different units (see Methods). The IPCC reported ${ }^{13}$ values based on carbon added from a one-time payment of US\$50 per $\mathrm{Mg}$ of $\mathrm{CO}_{2}$ or equivalent correspond to our annual payment of US\$1 with an interest rate of $0.55 \%$ or our annual payment of US\$10 with an interest rate of $5.5 \%$. The IPCC reported range for land use-based annual mitigation of $0.14-1.39 \mathrm{Pg}$ of carbon translates to $0.011-0.107 \mathrm{Mg}$ of carbon annually on every land hectare of the earth. Converting further to the mean carbon addition by weighting the near future more (discounting with 3\%) used in this study lead to $0.34-3.51 \mathrm{Mg}$ per hectare when assuming this mitigation rate to remain constant for the whole two hundred-year period. Assuming the 5.5\% interest rate, the upper end of the range is not far from the values of MexicoWest and TanzaniaEast, but much lower than the average of all ten landscapes (32.6 $\mathrm{Mg} \mathrm{ha}^{-1}$ ) (Table 1). Adding carbon into our landscapes assuming good governance was based on our study and a 5.5\% interest rate, and was between one and two orders of magnitude more cost-effective than the extremes of the range reported by IPCC ${ }^{13}$.

The reasons behind the substantial differences among the landscapes cannot be quantified, but the justifications of the interviewees revealed three main factors determining the perceived cost of increasing ecosystem carbon: 1) the large variation in the potential to increase carbon relative to the baseline future scenario, 2) the economics of the alternative land uses and opportunity costs of substituting them with higher carbon density land $u^{20}$ and 3) how the interviewees perceived the 
assumptions on good governance and efficient distribution of carbon funding. Payments assuming current governance conditions, which vary among landscapes ${ }^{21}$, would probably have yielded quite different results. FinlandNorth, where implementation of carbon addition projects would be straightforward, might be a more cost-effective landscape in which to allocate carbon funding compared to Indonesia, where various levels of government advance conflicting agendas ${ }^{22}$, and where recent attempts backed by substantial foreign funding have not been able to influence carbon density ${ }^{23}$.

The future role of land use in mitigating climate change is likely to depend largely on agricultural subsidies that have globally been several hundred times higher than REDD+ funding ${ }^{24,25}$ and have perversely incentivised land owners to keep ecosystems open, especially in wealthy countries. It seems possible that policies promoting increasing ecosystem carbon in rangelands, wastelands and other land uses spared from intensive crop production ${ }^{26}$ could greatly mitigate climate change without significantly reducing global food production.

\section{Methods}

\section{Workshops and landscapes}

Most of our research was associated with participatory workshops ${ }^{27,28}$ on land use that MKa, ML and AML organised as part of a collaboration between University of Helsinki, CIFOR (Center for International Forestry Research) and local organisations. Typically 20-30 participants ranging from national to local level and representing the government, private sector, NGO, and research organisations, participated in these two-day workshops, which developed alternative landscape scenarios using large printed land-use maps. The locations of these landscapes were not randomly chosen, but were located in areas where CIFOR had worked previously on land use and governance, and had established contacts in local communities. In general, the landscapes had been previously selected due to their varied land uses and rapid land-use changes, and therefore they tended to be more complex and dynamic than average. The two landscapes in each country were generally chosen to represent regions with differing drivers of deforestation and degradation.

Linking our interviews with the landscapes of the workshops was advantageous, as we obtained valuable land-use and carbon data from key workshop participants and understood more of the local land-use history and drivers of change thanks to participation in the workshops. This process enabled us to select the experts to be invited for interviewing. Of our ten landscapes, the eight tropical ones were the same as those used in the workshops, and in five of these areas our interviews were conducted during the days after the workshops.

We added the two Finnish landscapes to test the methods and to expand the data set to include a biome and continent not incorporated in the project that organised the participatory workshops. We chose the locations of the Finnish interviews to include one landscape representing the typical land use of southern Finland while the other represented northern Finland. 
Landscape borders are available in the Supplementary Data file LandscapeBorders.xlsx.

\section{CarboScen}

A programme named CarboScen was developed as a carbon calculation tool to compute mean carbon density in landscapes with changing land uses, particularly for future land-use scenarios ${ }^{29}$. In a static situation, mean carbon density could be simply computed by taking the mean carbon density values weighted by proportions of the land-use classes. However, when land uses change, simply using the carbon density of the new land use is misleading if carbon density changes slowly towards the new value. These changes are typically slow with soil organic carbon ${ }^{30,31}$ and when afforestation is involved ${ }^{32}$. Instead of the linear changes commonly used ${ }^{33}$, CarboScen assumes that carbon density approaches the new carbon density equilibrium asymptotically following:

$\rho_{c}=\rho_{s}+\left(\rho_{e}-\rho_{s}\right)\left(1-e^{-f t}\right)$,

where $\rho_{c}$ is carbon density of the cohort in question, $\rho_{s}$ is carbon density at the beginning of the examination period, $\rho_{e}$ is equilibrium carbon density of the land-use type in question, and $f$ is a parameter on transition speed. Land-use changes are coded in CarboScen in a land-use change matrix, and enable the rapid visualisation of changes suggested by the interviewed experts. CarboScen also allowed bootstrapping of uncertainty caused by variability in the carbon density estimates. For simplicity, CarboScen is for use on ecosystem carbon only, and does not include other climate impacts of land use such as carbon stored in products manufactured from wood originating from the landscape, the substitution of fossil fuels or products, emissions of methane and other secondary greenhouse gases, the production of volatile organic compounds, and albedo.

\section{Carbon data}

The workshops and interviews in the eight tropical landscapes were based on land-cover maps. We obtained the borders of the land coverage from these maps. We did not prepare maps for the Finnish landscapes, but as they had administrative limits, we obtained the land-use areas from national statistical sources.

We based the carbon density estimations for most landscapes on a large number of sources (Supplementary Data file CarbonDensity.xlsx). Normally, potential sources are classified in a binary way so that some are included and others not. Instead, we assigned weights to each carbon density value based on the trustworthiness and relevance of the data, and computed weighted arithmetic means. For example, data reported in well-known journals, based on most reliable methodology described in detail and from an ecosystem similar to the land-use type of the landscapes used in our study and located close by, received high weights.

The parameter values for the speed of carbon density transition (parameter $f$ above) was set at a plausible level based on meta-analyses ${ }^{30,31}$ and data that are now published ${ }^{32}$. 
ML visited and explored all the tropical landscapes for our research, and was already previously familiar with the Finnish landscapes.

\section{Reference scenarios and technical maximum}

We based the expert interviews on business-as-usual or reference land-use scenarios that were assumed to happen if funding to increase ecosystem carbon was not granted. The objective was not to meticulously develop the most likely scenarios, but rather to create a plausible scenario for the landscapes and simply let the experts assume that this is the future without carbon payments. Because the objective of our research was to quantify the impact of the carbon payments, even a large bias in the reference scenario relative to true future development would presumably lead to only a small bias in the opinions of the interviewed experts.

We computed the "technical maximum" scenarios (rightmost column in Table 1) by converting immediately all of the area to the land use with highest carbon density. Naturally, when the landscape had climatically or edaphically differing conditions, the conversion was to the land use with the highest carbon density of that elevation or soil class. We do recommend the meticulous comparison of the technical maximums, as they depend on our definitions, and there is no natural upper limit for adding ecosystem carbon e.g. in the form of biochar or coarse woody debris brought from elsewhere.

\section{Interviews}

When selecting the interviewees, the objective was to find the best experts primarily on land-use economics and land-use changes, but who also understood the very basics of ecosystem carbon and why it is valuable. In practice, this meant that nearly every interviewee for the eight tropical landscapes had worked in or close to the given landscapes for many years. Because Finland has much more homogenous land use and policy, the interviewees were experts of also more distant areas in their country. To avoid pseudoreplications, we did not interview more than one expert from each institution, and we attempted to balance the number of representatives from the government, NGOs, private sector and research.

Our objective was to conduct eight interviews per landscape, but due to difficulties we only completed seven interviews in MexicoEast and six in MexicoWest. We interviewed five nationallevel experts for both Finnish landscapes and one expert for both Indonesian landscapes, and thus completed 77 interviews with 71 experts. In a few cases the interviewees wished their colleagues to also be present. We allowed this, but stressed that the views should be those of the principal interviewee. The majority of the interviewees had participated in the workshops, which therefore facilitated the process, as they were familiar with identical landscape definitions and CarboScen. As the activities in the workshops were different, we do not believe that participation in them significantly influenced the experts' responses during the interviews. 
ML was the interviewer and MKa participated in most of the interviews in IndonesiaEast, IndonesiaWest, PeruSouth and TanzaniaEast. The interviews were held in Finnish in Finland, in Spanish in Mexico and Peru, mainly in English in Tanzania, but with the help of a KiswahiliEnglish translator during some of the interviews, and mainly in Indonesian and partly in English in Indonesia, with the help of an Indonesian-English translator. The risk of significant bias due to inadequate translation was minimal, as all interviewed Tanzanians understood English as well, and MKa could control the quality of the Indonesian-English translations. We did not record the interviews in order to keep a confidential and relaxed atmosphere, and to assure that the interviewee felt that he or she may respond freely to the questions based on his or her personal thinking, not influenced by the views of others.

If considered potentially useful, the interviewees were given a land-use map of the landscape to refer to during the interview. More importantly, the interviewees could watch either a laptop computer monitor or a projected screen picturing assumptions of carbon densities, land-use change, and additional carbon based on the changes they had suggested. The interviews were based on a set structure (Supplementary Box 2), but in practice ML presented the assumptions and questions in an informal discussion. The interviews began with a description of CarboScen, the landscape and the reference scenario. Each interviewee was asked to envision a reference scenario for the future land use, assuming no carbon funding was available. Next each interviewee was asked to imagine an annual payment of US\$1 for every additional $\mathrm{Mg}$ of carbon, and to describe the land-use changes that this payment could cause during the first thirty years.

Assumptions made during the interviews were that the payments would be adjusted for inflation, that they were coming from a global fund also in charge of carbon quantification, and that equivalent payments were given in all landscapes of the world. We additionally assumed that the payments are made to the central government of the country, but that an efficient distribution mechanism exists for the funding along with good governance. After making sure that the interviewee understood these assumptions, they were asked to envision a payment of US $\$ 1$ for every additional $\mathrm{Mg}$ of carbon, and to describe the land-use changes occurring as a result. ML then coded the changes suggested by each interviewee, and the additional carbon could then be seen on the screen. ML next asked whether these changes initially suggested were realistic and whether other possible land-use changes existed. This iterative process continued until the interviewee was satisfied with the land use scenario. The same process was then repeated, but with an assumed annual payment of US\$10 for every additional Mg of carbon. We chose the payments of US\$1 and US\$10 as they were round numbers and corresponded roughly to the range of payments made in various projects. We did not use the common consensus-seeking Delphi technique ${ }^{34}$, as we did not want to force the interviewees to justify their reasoning, and wanted to complete the data set collection with one visit.

\section{Analysis}


The analysis was straightforward, as we obtained the carbon implications of the alternative land-use scenarios from CarboScen, and compared them to those from reference land-use scenarios. Instead of comparing differences at a certain point of time or average differences until a certain point of time, as commonly done, we computed the average differences, but by weighting the proximate future more than the distant future. We discounted the weights with $3 \%{ }^{(35)}$, so that the first year influenced the average 3\% more than the second, and roughly as much as the twenty-third and twenty-fourth years combined. We did not include carbon implications beyond two hundred years in the future.

We used bootstrapping ${ }^{36}$ to quantify uncertainty in the discounted averages. The confidence intervals reported in Table 1, based on variation in the expert opinions, are based on the percentile method, and are computed with the R software environment ${ }^{37}$ and 10000 bootstraps, and the variation in carbon density data are computed in CarboScen ${ }^{29}$ with 1000 bootstraps. We could not compute the uncertainty from carbon density data for the Finnish and Indonesian landscapes, as carbon modelling was largely based on single data sources. Carbon estimation for some of the important land uses was also based only on a single value in some of the other landscapes, causing underestimation of the uncertainty.

\section{How to compare to costs reported in other studies?}

The cost of climate change mitigation is typically linked to perhaps the most natural unit when cutting emissions from fossil fuel usage: the annual reduction in $\mathrm{CO}_{2}$ emissions. This is a natural unit also for land use-based estimations if the harm caused by mitigation is the loss of timber revenue from an unsustainable clear-cut. However, more typically the envisioned loss is from a stream of revenue e.g. from the annual harvest of agricultural crops. Then future revenues would need to be discounted to present day value to compare with the carbon payment of the lost opportunities. Using the carbon rental approach ${ }^{38}$ is more straightforward in these cases. In this approach future revenues from lost opportunities can be directly compared to the carbon payments. An additional benefit of this approach is that it cannot lead to payments back to the donor (except in some theoretical cases), which would be difficult to implement in the least developed countries.

These two approaches are comparable assuming a fixed interest rate and very long simulation period. The annual payment for additional carbon can be perceived as the interest for capital received from one-time payments. Therefore, e.g. with an interest rate of $10 \%$, the annual interest from a one-time payment of US\$10 is US\$1, equivalent to an annual carbon payment of US\$1. Because $\mathrm{CO}_{2}$ contains oxygen in addition to carbon, its mass is multiplied by $3 / 11$ to obtain the mass of carbon only. To convert global values to land area-based values, the global potential can be divided e.g. by the total land area of 13 billion ha, or a smaller region if the focus is e.g. on the tropics only. Finally, our reported numbers (Table 1) are weighted mean additions. Therefore, for conversion, the period for which the constant ecosystem carbon addition is made needs to be defined, and the weighted mean addition after discounting weights with $3 \%$ must be computed as explained above. 


\section{References (bullets and EndNote links removed before submission)}

- 1 Stern, N. The economics of climate change: the Stern review. (cambridge University press, 2007).

- 2 Lubowski, R. N. \& Rose, S. K. The potential for REDD+: Key economic modeling insights and issues. Review of Environmental Economics and Policy 7, 67-90 (2013).

- 3 Kremen, C. et al. Economic incentives for rain forest conservation across scales. Science 288, 1828-1832 (2000).

- 4 Santilli, M. et al. Tropical deforestation and the Kyoto Protocol. Climatic Change 71, 267-276 (2005).

- 5 Sills, E. O. et al. REDD+ on the ground: A case book of subnational initiatives across the globe. (CIFOR, 2014).

- 6 Fletcher, R., Dressler, W., Büscher, B. \& Anderson, Z. R. Questioning REDD+ and the future of market-based conservation. Conservation Biology (2016).

- 7 UN-FCCC. Adoption of the Paris agreement, 2015).

- 8 Grieg-Gran, M. The cost of avoiding deforestation: Update of the report prepared for the Stern Review of the Economics of Climate Change. (2008).

- 9 Jack, B. K., Leimona, B. \& Ferraro, P. J. A revealed preference approach to estimating supply curves for ecosystem services: use of auctions to set payments for soil erosion control in Indonesia. Conservation Biology 23, 359-367 (2009).

- 10 Börner, J. et al. Direct conservation payments in the Brazilian Amazon: Scope and equity implications. Ecological Economics 69, 1272-1282 (2010).

- 11 Kindermann, G. et al. Global cost estimates of reducing carbon emissions through avoided deforestation. Proceedings of the National Academy of Sciences 105, 10302-10307 (2008).

- 12 Ickowitz, A., Sills, E. \& de Sassi, C. Estimating Smallholder Opportunity Costs of REDD+: A Pantropical Analysis from Households to Carbon and Back. World development 95, 15-26 (2017).

- 13 Change, I. P. o. C. Climate Change 2014: Mitigation of Climate Change. Vol. 3 (Cambridge University Press, 2014).

- 14 Fisher, B. et al. Implementation and opportunity costs of reducing deforestation and forest degradation in Tanzania. Nature Climate Change 1, 161-164 (2011).

- 15 Rose, S. K. et al. Land-based mitigation in climate stabilization. Energy Economics 34, 365-380 (2012).

- 16 Larjavaara, M., Kanninen, M., Alam, S. A., Mäkinen, A. \& Poeplau, C. CarboScen: a tool to estimate carbon implications of land-use scenarios. Ecography, n/a-n/a, doi:10.1111/ecog.02576 (2017).

- 17 Hooijer, A. et al. Subsidence and carbon loss in drained tropical peatlands. (2012).

- 18 Huijnen, V. et al. Fire carbon emissions over maritime southeast Asia in 2015 largest since 1997. Scientific reports 6, 26886 (2016).

- 19 Beer, J. Advantages, disadvantages and desirable characteristics of shade trees for coffee, cacao and tea. Agroforestry systems 5, 3-13 (1987).

- 20 Clough, Y. et al. Land-use choices follow profitability at the expense of ecological functions in Indonesian smallholder landscapes. Nature Communications 7 (2016).

- 21 Indicators, W. G. The World Bank Group. The World Bank Group (2016).

- 22 Myers, R., Sanders, A. J., Larson, A. M. \& Ravikumar, A. Analyzing multilevel governance in Indonesia: Lessons for REDD+ from the study of landuse change in Central and West Kalimantan. Vol. 202 (CIFOR, 2016).

- 23 Sanders, A. J., da Silva Hyldmo, H., Ford, R. M., Larson, A. M. \& Keenan, R. J. Guinea pig or pioneer: Translating global environmental objectives through to local actions in Central Kalimantan, Indonesia's REDD+ pilot province. Global Environmental Change 42, 68-81 (2017). 
- 24 Trade, O. Agricultural Policy Monitoring and Evaluation 2015: OECD Countries and Emerging Economies. (OECD publ., 2013).

- 25 Norman, M. \& Nakhooda, S. The state of REDD+ finance. CGD Climate and Forest Paper series 5 (2014).

- 26 Lamb, A. et al. The potential for land sparing to o set greenhouse gas emissions from agriculture. (2016).

- 27 Ravikumar, A., Gonzales, J., Kowler, L. F. \& Larson, A. M. Building future scenarios: Governance, land use and carbon management at the landscape scale. (Center for International Forestry Research (CIFOR), 2014).

- $\quad 28 \quad$ Ravikumar, A., Larjavaara, M., Larson, A. \& Kanninen, M. Can conservation funding be left to carbon finance? Evidence from participatory future land use scenarios in Peru, Indonesia, Tanzania, and Mexico. Environmental Research Letters 12, doi:10.1088/1748-9326/aa5509 (2017).

- 29 Larjavaara, M., Kanninen, M., Alam, S. A., Mäkinen, A. \& Poeplau, C. CarboScen: A tool to estimate carbon implications of landuse scenarios. Ecography (In press).

- 30 Poeplau, C. et al. Temporal dynamics of soil organic carbon after land-use change in the temperate zone - carbon response functions as a model approach. Global Change Biology 17, 24152427, doi:10.1111/j.1365-2486.2011.02408.x (2011).

- $\quad 31$ Wei, X., Shao, M., Gale, W. \& Li, L. Global pattern of soil carbon losses due to the conversion of forests to agricultural land. Scientific Reports 4, doi:10.1038/srep04062 (2014).

- $\quad 32$ Anderson-Teixeira, K. J., Wang, M. M. H., McGarvey, J. C. \& LeBauer, D. S. Carbon dynamics of mature and regrowth tropical forests derived from a pantropical database (TropForC-db). Global Change Biology 22, 1690-1709, doi:10.1111/gcb.13226 (2016).

- $\quad 33 \quad$ IPCC. Guidelines for National Greenhouse Gas Invetories. (2006).

- $\quad 34 \quad$ Linstone, H. A. \& Turoff, M. The Delphi method: Techniques and applications. Vol. 29 (Addison-Wesley Reading, MA, 1975).

- 35 Nordhaus, W. D. Discounting in economics and climate change; an editorial comment. Climatic Change 37, 315-328 (1997).

- $\quad 36$ Hillis, D. M. \& Bull, J. J. An empirical test of bootstrapping as a method for assessing confidence in phylogenetic analysis. Systematic biology 42, 182-192 (1993).

- $\quad 37 \quad \mathrm{R}$ Development-Core-Team. $R$ : A language and environment for statistical computing. ( $\mathrm{R}$ Foundation for Statistical Computing, 2008).

- 38 Sohngen, B. \& Mendelsohn, R. An optimal control model of forest carbon sequestration. American Journal of Agricultural Economics 85, 448-457 (2003).

\section{Supplementary Information is available in the online version of the paper}

\section{Acknowledgements}

We thank the Norwegian Agency for Development Cooperation (Norad) for funding, Arttu Pienimäki and Piero E. Rengifo for pivotal contributions on carbon and land-use data, Claudia Bergroth, Elias Willberg, David Gaveau, Husna Yaen and Sakari Tuominen for assistance with land-use and carbon data, Laura F. Kowler, Jazmin Gonzales Tovar, Yulius Saden, Arang Lorens, Mohammed Habib, Martin H. Kijazi, Israel Amezcua Torrijos, Tim Trench, Rodd Myers, Ashwin Ravikumar and Adrián A. Monge Monge for assistance in selecting and arranging the interviews, Kaisa Korhonen-Kurki, Aapo Rautiainen, Salla Rantala and Paavo Ojanen for discussions and comments on the manuscript, Stella Thompson for linguistic editing, and the 71 interviewed experts of whom the following were willing to reveal their names listed in alphabetic order: Erno Järvinen, 
Danielson R. Kisanga, Anggela Michi Quijano, Kassim Mohammed Muombwa, Antti Puhalainen, and Piero E. Rengifo.

\section{Author Contributions}

MKa raised the funding, ML and MKa developed the research idea, ML, HGR, MKu, JK, NK and MKa worked on the land-use and carbon data, ML and MKa performed the interviews, ML analysed the data and wrote the first draft of the main manuscript, ML, MKu, JK wrote the first draft of the Supplementary Methods, and ML, SW, AML, MKu, NK and JK edited the draft to produce the final version.

\section{Author Information}

Practically all data are available as Supplementary Data or as Supplementary Tables in the Supplementary Methods. Reprints and permission information is available at www.nature.com/reprints. The authors declare no competing financial interests. Readers are welcome to comment on the online version of the paper. Correspondence should be addressed to ML (markku.larjavaara@gmail.com). 


\section{Tables}

Table 1. Initial ecosystem carbon densities and potential additions in $\mathbf{M g ~ h a}^{-1}$. We computed additions for 2015-2214 by discounting weights with 3\%, so that that the closer the addition is in the future, the more it impacts the value.

\begin{tabular}{|c|c|c|c|c|c|c|c|}
\hline & \multicolumn{2}{|c|}{ Carbon density 2015} & \multicolumn{2}{|c|}{$\begin{array}{l}\text { Additional carbon } \\
\text { density, US\$1, all } \\
\text { interviewees }\end{array}$} & \multicolumn{2}{|c|}{$\begin{array}{l}\text { Additional carbon } \\
\text { density, US\$10, all } \\
\text { interviewees }\end{array}$} & \multirow{2}{*}{$\begin{array}{l}\begin{array}{l}\text { Additional } \\
\text { carbon } \\
\text { density, } \\
\text { maximal }\end{array} \\
\text { Based on } \\
\text { weighted } \\
\text { mean } \\
\text { carbon } \\
\text { densities }\end{array}$} \\
\hline & $\begin{array}{l}\text { Weighted } \\
\text { mean }\end{array}$ & $\begin{array}{l}\text { Confidence } \\
\text { interval based } \\
\text { on variation in } \\
\text { carbon } \\
\text { density data }\end{array}$ & Mean & $\begin{array}{l}\text { Confidence } \\
\text { interval based } \\
\text { on variation in } \\
\text { expert } \\
\text { opinions }\end{array}$ & Mean & $\begin{array}{l}\text { Confidence } \\
\text { interval based } \\
\text { on variation in } \\
\text { expert } \\
\text { opinions }\end{array}$ & \\
\hline FinlandNorth & 129.5 & $N A$ & 4.3 & $2.1-6.6$ & 14.5 & $10.3-19.4$ & 28.1 \\
\hline FinlandSouth & 108.5 & $N A$ & 3.5 & $2.1-5.3$ & 8.9 & $6.9-11.1$ & 35.0 \\
\hline IndonesiaEast & 4607.6 & $N A$ & 105.6 & $43.6-169.7$ & 150.3 & $60.9-240.8$ & 492.0 \\
\hline IndonesiaWest & 1933.7 & $N A$ & 36.6 & $7.6-72.2$ & 111.0 & $67.7-154.5$ & 392.2 \\
\hline MexicoEast & 150.8 & $136.5-159.8$ & 2.0 & $0.4-4.5$ & 7.3 & $2.8-12.2$ & 44.7 \\
\hline MexicoWest & 94.5 & $82.7-117.1$ & 0.2 & $0.0-0.5$ & 2.7 & $1.2-4.4$ & 18.2 \\
\hline PeruNorth & 160.2 & $133.8-337.3$ & 3.3 & $1.6-5.2$ & 8.7 & $6.5-11.1$ & 30.4 \\
\hline PeruSouth & 165.7 & $157.8-175.0$ & 4.1 & $2.3-6.2$ & 10.4 & $8.5-12.2$ & 32.9 \\
\hline TanzaniaEast & 79.6 & $77.2-85.2$ & 1.1 & $0.4-1.9$ & 2.8 & $1.7-3.8$ & 31.0 \\
\hline TanzaniaWest & 63.5 & $45.6-109.3$ & 4.2 & $2.0-6.8$ & 9.7 & $5.9-13.7$ & 45.4 \\
\hline
\end{tabular}




\section{Figures}
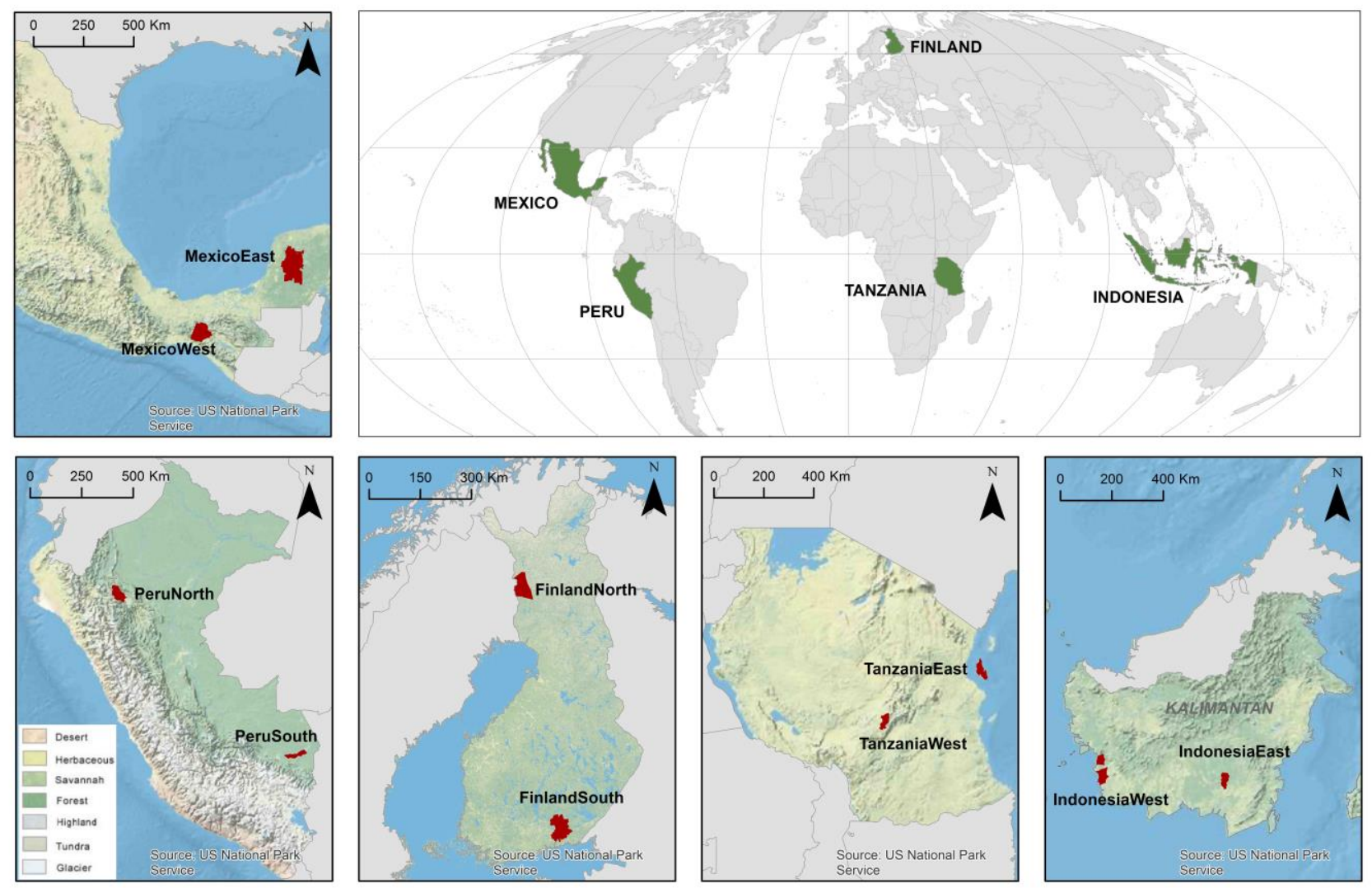

Figure 1. Location of the ten landscapes (red in small panels) in the five countries included (green in large panel). 


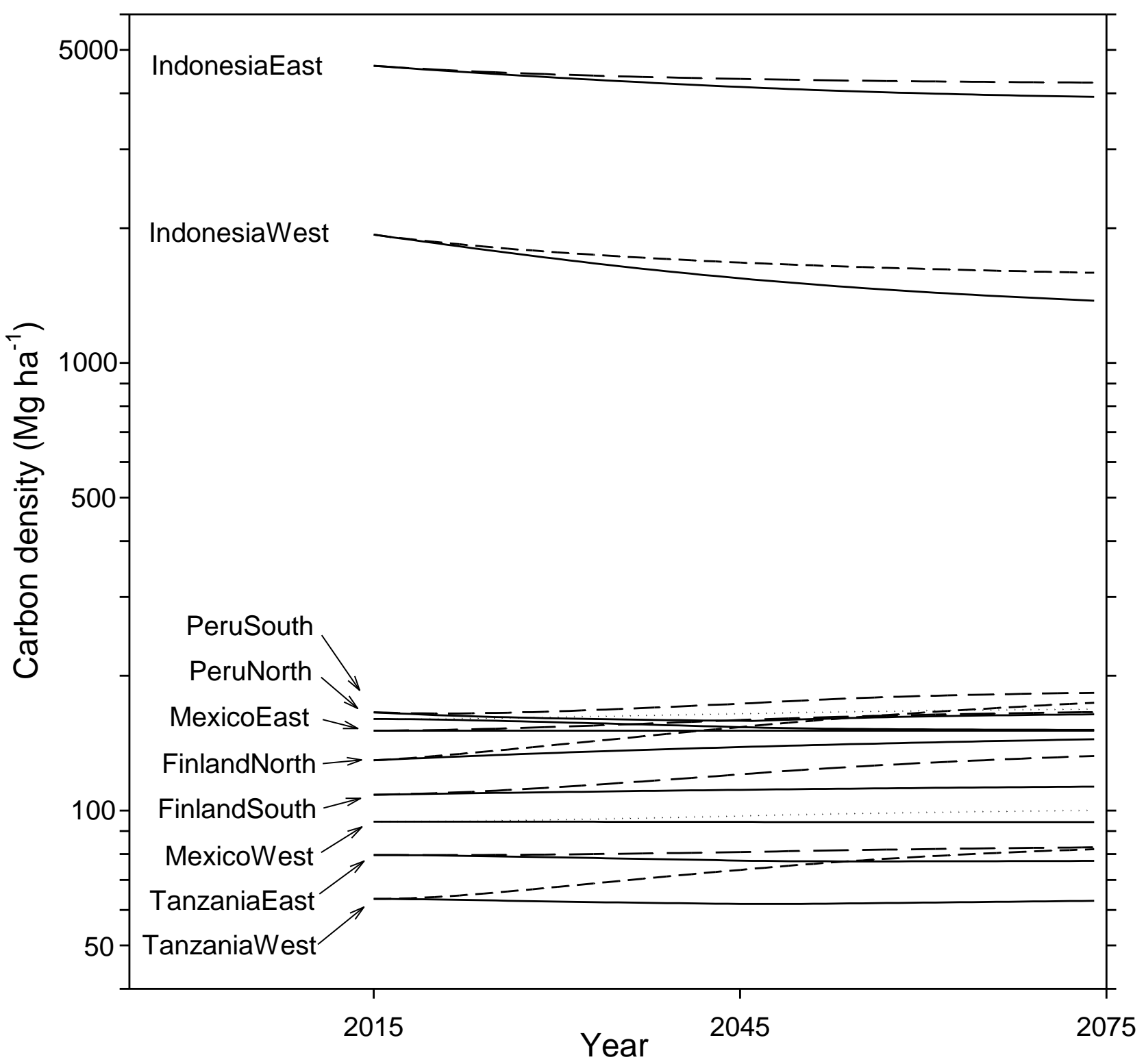

Figure 2. Carbon densities in the studied landscapes during the first sixty years of the simulation. Solid lines mark the baseline scenarios and dashed lines the scenario with the assumed US\$10 annual payment for every additional Mg of ecosystem carbon. 


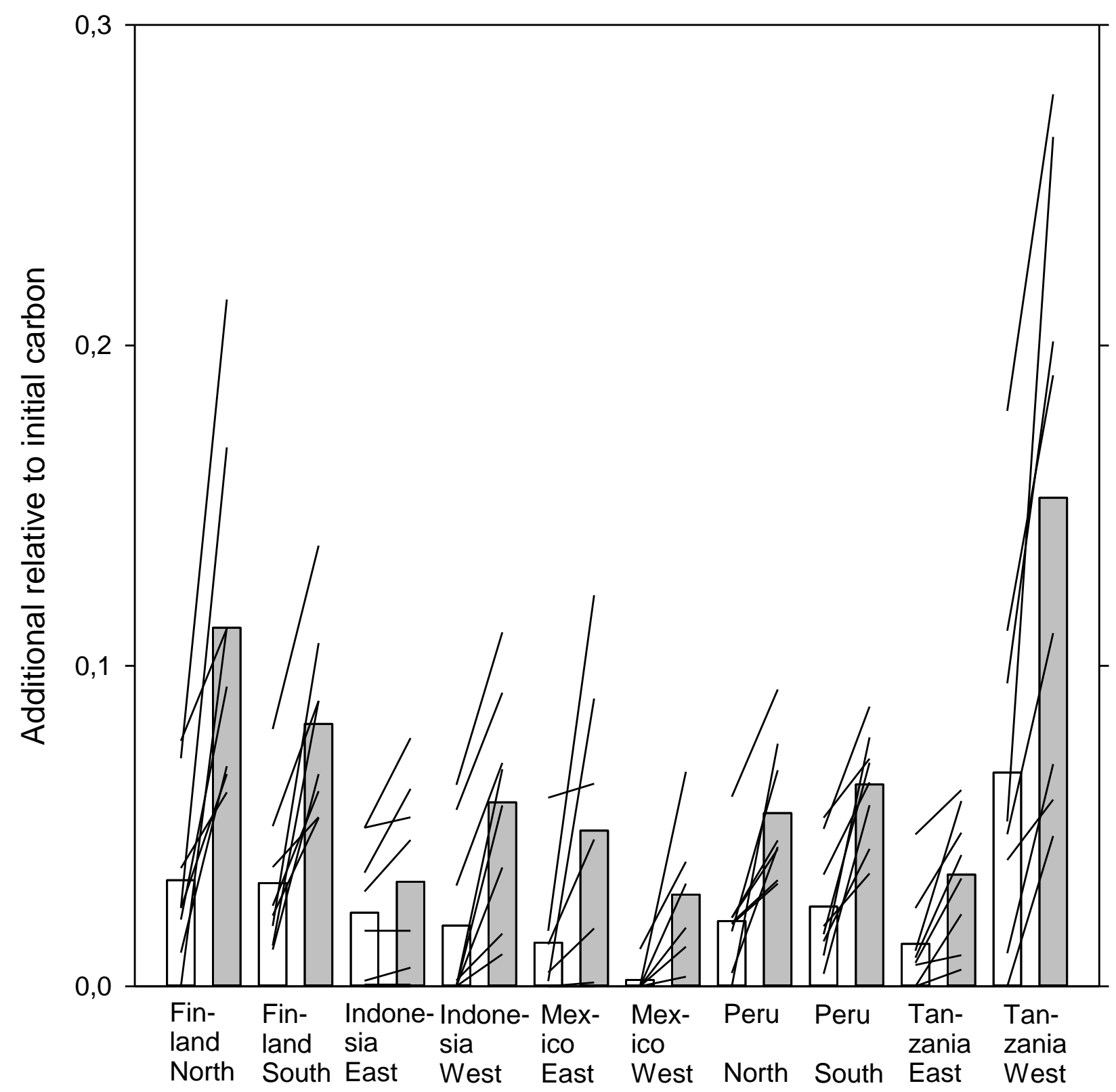

Figure 3. Potential carbon additions as a result of payments relative to the initial by discounting weights with $3 \%$. White bars (left) represent mean expert opinion with an imagined payment of US\$1 and grey bars (right) the mean with a payment of US $\$ 10$. The lines show responses from individual interviewees from which the means were computed. 